Volume 5 Nomor 2, Agustus 2020, halaman 195-204.

\title{
BLENDED LEARNING: KEMAMPUAN BERPIKIR KRITIS, SELF CONCEPT, DAN MATHEMATICS ANXIETY PADA MATA KULIAH ALJABAR ABSTRAK
}

\section{BLENDED LEARNING: CRITICAL THINKING ABILITY, SELF CONCEPT, AND ANXIETY MATHEMATICS IN ALGEBRA COURSE ABSTRACT}

\author{
Mellawaty ${ }^{1}$, Mochammad Taufan ${ }^{2}$ \\ ${ }^{1}$ Universitas Wiralodra, Jalan Ir. H. Juanda KM 3 Singaraja, Indramayu, Indonesia. \\ mellawaty@unwir.ac.id \\ ${ }^{2}$ Universitas Wiralodra, Jalan Ir. H. Juanda KM 3 Singaraja, Indramayu, Indonesia. \\ mochammad.taufan@unwir.ac.id
}

\begin{abstract}
ABSTRAK
Artikel ini mendeskripsikan studi mengenai kemampuan berpikir kritis matematis, self concept, dan mathematics anxiety calon guru matematika pada mata kuliah aljabar abstrak teori ring dengan penggunaan model pembelajaran blended learning pada masa pandemi covid-19 di Indramayu, Jawa Barat. Metode penelitian yang digunakan adalah kuantitatif dengan desain one-group pretestposttest dan pengumpulan data dilakukan dengan lembar kerja dan angket. 19 calon guru matematika terlibat selama penelitian. Hasil penelitian mengungkapkan bahwa blended learning mampu mempengaruhi kemampuan berpikir kritis matematis, self concep, dan mathematics anxiety calon guru matematika yang mengampu mata kuliah aljabar abstrak selama masa pandemi covid-19 di Indramayu, Jawa Barat. Adapun kesulitan yang dialami oleh calon guru matematika dalam pembelajaran blended learning selama masa pandemi covid-19 di Indramayu, Jawa Barat, yaitu yang berkaitan dengan pembelajaran online dimana sampel terkendala oleh jaringan internet, kuota internet, serta kesiapan pelaksanaan proses pembelajaran dalam mata kuliah aljabar abstrak teori ring. Hal ini disebabkan karena sampel berasal dari keluarga menengah kebawah sehingga mereka terkendala biaya untuk kuota internet. Selain itu, 90\% sampel berasal dari daerah Indramayu yang berbatasan dengan kabupaten disekitar, dimana akses jaringan internet masih sulit digunakan.
\end{abstract}

Kata Kunci : Berpikir Kritis, Blended Learning, Aljabar Abstrak.

\section{ABSTRACT}

This paper reports a study on mathematical critical thinking ability, self-concept, and mathematics anxiety of mathematics pre-service teachers in the abstract algebra courses using the blended learning model during the Covid-19 pandemic Indramayu, West Java. Data collection was carried out using worksheets and questionnaires. Nineteen pre-service mathematics teachers were involved during the study. The results revealed that blended learning influenced mathematical critical thinking ability, self-concept, and mathematics anxiety of pre-service mathematics teachers who taught the abstract algebra courses during the Covid-19 pandemic in Indramayu, West Java. The difficulties experienced by pre-service mathematics teachers in blended learning during the Covid19 epidemic in Indramayu, West Java, namely those related to online education where the sample was constrained by internet networks, internet quotas, and readiness to implement the learning process in abstract algebra courses. This is because the selection comes from middle to lower class families so that the cost of internet quota constrains them. Also, $90 \%$ of samples from the Indramayu area bordered the surrounding districts, where the Internet network access is still difficult to use.

Keyword(s): Critical Thinking, Blended Learning, Algebra Abstract. 
How to Cite: Mellawaty, N., \& Taufan, M. (2020). Blended Learning: Kemampuan Berpikir Kritis, Self Concept, dan Mathematics Anxiety Pada Mata Kuliah Aljabar Abstrak. Mathline: Jurnal Matematika dan Pendidikan Matematika, Vol. 5 No. 2, 195 - 204.

DOI: $\underline{\text { https://doi.org/10.31943/mathline.v5i2.160 }}$

\section{PENDAHULUAN}

Kementerian Pendidikan dan Kebudayaan Republik Indonesia meliburkan semua kegiatan belajar mengajar dari tingkat sekolah dasar sampai dengan tingkat perguruan tinggi diseluruh wilayah Indonesia untuk turut melakukan kewajiban dari program pemerintah dipusat dalam rangka mencegah dan menanggulangi penularan Covid-19 yang semakin hari semakin meningkat dan memakan banyak korban baik usia dini sampai usia lanjut. Pemerintah Republik Indonesia membuat peraturan yang wajib dilaksanakan oleh seluruh rakyat Indonesia dengan melakukan pembatasan jarak sosial (social distancing) dan pembatasan jarak fisik (physical distancing) diseluruh lapisan lingkungan belajar dan instansi kerja sejak bulan maret 2020. Oleh karena itu, proses perkuliahan yang telah dilaksanakan untuk beberapa kali secara tatap muka, diubah langsung dengan pertemuan perkuliahan menjadi pembelajaran jarak jauh dengan memanfaatkan berbagai teknologi yang ada dan sesuai dengan kondisi dosen dan mahasiswa. Hal ini secara langsung memberikan persepsi bahwa teknologi dijadikan sebagai media pembelajaran yang sangat penting yang dalam pelaksanaannya mampu menjadi perantara atau menjembatani proses belajar tatap muka diantara guru dengan siswa. Pendapat ini sejalan dengan pendapat (Anthony et al., 2019; Borba et al., 2016; Csp \& Becker, 2020; Fadillah, Nopitasari, Pradja, 2020; Hall, 2006) yang menyatakan bahwa teknologi sebagai media perantara bagi guru dan siswa.

Penggunaan teknologi juga masih perlu diperhatikan ketika mengembangkan peroses pembelajaran blended learning, seperti mobile learning (Faradillah \& Hadi, 2020). Adapun pilihan untuk pembelajaran tatap muka pada pelaksanaan model pembelajaran blended learning di program studi pendidikan matematika Universitas Wiralodra yaitu dilakukan dengan melalui aplikasi zoom, email, google schoolar dan whatsapp. Hal ini sejalan dengan penelitian (Dakduk, Santalla-Banderali, \& van der Woude, 2018; Elyakim, Reychav, Offir, \& McHaney, 2019; Wai \& Seng, 2015) yang menyatakan bahwa model pembelajaran blended learning itu dapat dilakukan secara mandiri baik melalui media audio, video, diskusi online, kuis, tugas, email, dan ataupun percakapan langsung, sehingga 
pelaksanaan model blended learning akan lebih fleksibel karena menyesuaikan dengan kondisi di lapangan. Selain itu, pelaksanaan tersebut akan mampu meningkatkan keterampilan serta dapat mengatasi cara belajar masing-masing individu yang berbedabeda.

Kemampuan berpikir kritis menjadi salah satu kemampuan yang penting yang harus dimiliki dan dikuasai oleh seseorang,hal tersebut bermanfaat dalam membantu untuk menyelesaikan permasalahan yang semakin kompleks dan rumit pada masa sekarang ini (Rasiman, 2006). Tetapi pada kenyataanya, masih banyak dijumpai kemampuan berpikir kritis masih rendah, hal ini terlihat dari hasil studi pendahuluan terhadap mahasiswa di prodi pendidikan matematika Universitas Wiralodra. Selain itu, masalah tersebut juga ditunjukkan dari penelitian (Prihartini, Lestari, \& Saputri, 2016; Saputra, 2020) yang menyebutkan bahwa rendahnya kemampuan berpikir kritis matematis itu salah satunya disebabkan oleh proses pembelajaran yang mono arah atau teacher centered, yaitu informasi hanya diperoleh dari guru saja. Selain itu, penyebab lainnya adalah siswa kurang diberikan kebebasan, keleluasaan, dan juga kesempatan untuk menggali, mengeksplor, menemukan, dan serta menganalisis ide-ide baru yang telah mereka dapatkan. Hal tersebut dapat memberikan pengaruh terhadap aspek psikologi, dalam hal ini self concept dan mathematics anxiety.

Menurut (Rahman, 2012), dikarenakan pandangan individu mengenai dirinya sendiri itu dipengaruhi oleh bagaimana individu itu sendiri dalam mengartikan pandangan orang lain terhadap dirinya, sudah seharusnya menjadi keadaan yang alami dimana pada setiap manusia memang ditakdirkan memiliki kemampuan yang berbeda-beda. Menurut (Silvernail, 1985), hal ini dapat terjadi karena manusia itu pada dasarnya mereka memiliki kemampuan untuk merefleksi dirinya sendiri baik dalam kehidupan ataupun dalam proses pendidikan dimana hal ini yang disebut dengan "self-concept". Self concept itu sendiri merupakan sebuah sistem, yang terdiri dari facet-facet yang saling terstruktur, terorganisir, serta saling berhubungan satu sama lain, sehingga hal ini yang dinamakan sebagai proses yang bersifat hirarkis (Rahman, 2012). Dikarenakan self concept bersifat hirarkhis, maka self concept itu dapat dideskripsikan serta juga dapat dinilai.

Menurut (Ganal, Guiab, \& Strategi, 2020), strategi motivasi dan emosional itu akan mampu mempengaruhi proses pembelajaran yang dilaksanakan oleh guru dan siswa. Hal tersebut akan mendorong keinginan dari dalam diri siswa untuk mencapai suatu tujuan yang mereka harapkan. Adapun kekuatan yang dihasilkannya itu akan berimbas dalam memengaruhi durasi atau waktu, dan intensitas tindakan yang dilakukan secara sadar. 
Banyak literatur yang menawarkan kegiatan-kegiatan dan juga pengetahuan baru untuk memastikan bahwa kegiatan pembelajaran yang mampu meningkatkan serta mempengaruhi kemampuan berpikir kritis mahasiswa. Salah satunya adalah pembelajaran blended learning, dimana pembelajaran tersebut menyatakan mampu mempengaruhi kemampuan berpikir kritis, self concept, dan mathematics anxiety, sehingga memungkinkan dosen untuk melaksanakan tugasnya secara optimal.

\section{METODE PENELITIAN}

Penelitian kuantitatif yang dilakukan dengan menggunakan desain one-group pretest-posttest ini dilakukan melibatkan 19 mahasiswa prodi pendidikan matematika semester 4 di FKIP Universitas Wiralodra (King, 1991). Subjek dipilih dengan teknik random sampling. Instrumen penelitian yang digunakan dalam penelitian ini yaitu tes kemampuan berpikir kritis, angket self concept dan mathematics anxiety. Desain analisis data adalah one-group pretest-posttest. Oleh karena itu desainnya seperti pada Gambar 1.

$$
\mathrm{O}_{1} \quad \mathrm{X} \quad \mathrm{O}_{2}
$$

Gambar 1. One-group Pretest-posttest Design

Rancangan one group pretest-posttest dengan rincian $\mathrm{O}_{1}$ dan $\mathrm{O}_{2}$ merupakan mahasiswa yang mengampu mata kuliah aljabar abstrak. X merupakan pembelajaran blended learning. Hasil pembelajaran dengan blended learning dilakukan dengan uji normalitas data dan dilanjutkan uji-t yang dilakukan dengan menggunakan SPSS Window 20.

\section{HASIL DAN PEMBAHASAN}

Pada bagian ini mendeskripsikan hasil penelitian dan pembahasan yang dihubungkan dengan studi dan teori yang relevan. Data hasil penelitian yang berhasil dikumpulkan dari proses pembelajaran blended learning berupa data skor pretest dan data skor posttest dianalisis untuk mengetahui pengaruhnya. Pada penelitian ini taraf kepercayaan yang digunakan adalah $95 \%$ atau $\alpha=5 \%$. Data skor pretest diperoleh dari tes awal yang diberikan sebelum pembelajaran. Tabel 1 berikut memetakan skor normalitas dari kemampuan berpikir kritis, self concept, dan mathematics anxiety: 
Tabel 1. One-Sample Kolmogorov-Smirnov Test

\begin{tabular}{llrrr}
\hline & & $\begin{array}{c}\text { Kemampuan } \\
\text { Berpikir Kritis }\end{array}$ & Self Concept & $\begin{array}{r}\text { Mathematics } \\
\text { Anxiety }\end{array}$ \\
\hline $\mathrm{N}$ & & 19 & 19 & 19 \\
Normal Parameters & & 78.1053 & 114.6842 & 44.2632 \\
& Mean & 9.38021 & 5.29206 & 4.36962 \\
& Std. Deviation & .227 & .072 & .156 \\
& Absolute & .227 & .068 & .095 \\
Most Extreme Differences & Positive & -.194 & -.072 & -.156 \\
& Negative & .991 & .313 & .678 \\
Kolmogorov-Smirnov Z & & .280 & 1.000 & .748 \\
Asymp. Sig. (2-tailed) & & & & \\
\hline a. Test distribution is Normal. & & & & \\
b. Calculated from data. & & & &
\end{tabular}

Berdasarkan hasil perhitungan SPSS di atas, diperoleh kesimpulan bahwa: (1) nilai signifikansi kemampuan berpikir kritis sebesar 0,280>0,05, sehingga sebaran data kemampuan berpikir kritis berdistribusi normal; (2) nilai signifikansi self concept sebesar $1,000>0,05$, sehingga sebaran data self concept berdistribusi normal; dan nilai signifikansi mathematics anxiety sebesar 0,748>0,05, sehingga sebaran data mathematics anxiety berdistribusi normal.

Tabel 2. One-Sample Statistics

\begin{tabular}{|c|c|c|c|c|c|c|}
\hline & & & $\mathrm{N}$ & Mean & Std. Deviation & $\begin{array}{l}\text { Std. } \\
\text { Error } \\
\text { Mean }\end{array}$ \\
\hline \multirow[t]{5}{*}{ Kemampuan B } & rpikir Kri & & & 78.10 & 9.38021 & 2.15197 \\
\hline & \multicolumn{5}{|c|}{ Tabel 3. One-Sample Test } & \\
\hline & \multicolumn{6}{|c|}{ Test Value $=70$} \\
\hline & \multirow[t]{2}{*}{$\mathrm{T}$} & \multirow[t]{2}{*}{$d f$} & \multirow[t]{2}{*}{$\begin{array}{l}\text { Sig. }(2- \\
\text { tailed) }\end{array}$} & \multirow[t]{2}{*}{$\begin{array}{c}\text { Mean } \\
\text { Difference }\end{array}$} & \multicolumn{2}{|c|}{$\begin{array}{c}95 \% \text { Confidence Interval of } \\
\text { the Difference } \\
\end{array}$} \\
\hline & & & & & Lower & Jpper \\
\hline $\begin{array}{l}\text { Kemampuan } \\
\text { Berpikir Kritis }\end{array}$ & 3.766 & 18 & .001 & 8.10526 & 3.5841 & 12.6264 \\
\hline
\end{tabular}

Berdasarkan hasil perhitungan SPSS di atas, diperoleh nilai signifikansi kemampuan berpikir kritis sebesar 0,001 $<0,05$, sehingga dapat diperoleh kesimpulan bahwa terdapat pengaruh model pembelajaran blended learning terhadap kemampuan berpikir kritis. Hasil penelitian ini sejalan dengan penelitian (Anggraeni, Supriana, \& 
Hidayat, 2019; Huda et al., 2019; Maryam, 2018; Nugraha, Astawa, \& Ardana, 2019) yang menyatakan bahwa penggunaan pembelajaran blended learning mempunyai pengaruh terhadap kemampuan berpikir kritis. Penggunan pembelajaran blended learning mampu memberikan pengaruh terhadap kemampuan berpikir kritis mahasiswa berdasarkan hasil analisis tersebut. Dalam mengolah informasi itu terdiri atas tiga karakteristik, yaitu meliputi kegiatan dari proses berpikir, mekanisme pengubah, dan juga modifikasi diri. Apabila mahasiswa tidak mampu merecall untuk memproses dan juga menggunakan pengetahuan lama yang disimpan dan telah dipelajarinya untuk menyesuaikan dengan respon terhadap pembelajaran baru, maka hasil pembelajaran blended learning tidak berpengaruh terhadap kemampuan berpikir kritis.

Adapun hasil Uji-T dari self concept, dapat dilihat dari tabel berikut.

Tabel 4. One-Sample Statistics

\begin{tabular}{lrrrr}
\hline & $N$ & Mean & Std. Deviation & \multicolumn{1}{c}{ Std. Error Mean } \\
\hline Self Concept & 19 & 114.6842 & 5.29206 & 1.21408 \\
\hline
\end{tabular}

Tabel 5. One-Sample Test

\begin{tabular}{|c|c|c|c|c|c|c|}
\hline & \multicolumn{6}{|c|}{ Test Value $=105$} \\
\hline & \multirow[t]{2}{*}{$\mathrm{t}$} & \multirow[t]{2}{*}{ Df } & \multirow[t]{2}{*}{$\begin{array}{l}\text { Sig. (2- } \\
\text { tailed) }\end{array}$} & \multirow[t]{2}{*}{$\begin{array}{c}\text { Mean } \\
\text { Difference }\end{array}$} & \multicolumn{2}{|c|}{$\begin{array}{c}95 \% \text { Confidence } \\
\text { Interval of the } \\
\text { Difference }\end{array}$} \\
\hline & & & & & Lower & Upper \\
\hline Self Concept & 7.977 & 18 & .000 & 9.68421 & 7.1335 & 12.2349 \\
\hline
\end{tabular}

Berdasarkan hasil perhitungan SPSS di atas, diperoleh nilai signifikansi self concept yaitu $0,000<0,05$, sehingga dapat diperoleh kesimpulan bahwa terdapat pengaruh model pembelajaran Blended Learning terhadap Self Concept. Hasil penelitian ini sejalan dengan penelitian yang dilakukan oleh (Khilmi R, 2020; Nugraha et al., 2019; Rahman, 2012) dimana mereka menyebutkan bahwa model pembelajaran blended learning mempengaruhi self concept mahasiswa. Proses pembelajaran yang bersifat student centered dapat berpengaruh dan mampu membuat self concept mahasiswa akan menjadi lebih baik. Salah satu usaha yang mampu dilaksanakan oleh dosen supaya kegiatan pembelajaran itu bersifat student centered adalah pembelajaran blended learning. Dengan pembelajaran blended learning, mahasiswa akan mampu membantu untuk memperoleh kedalaman materi yang mahasiswa inginkan. Mahasiswa dapat berhenti dan atau 
melanjutkan proses pendalaman materi itu sesuai dengan tingkat penguasaan mahasiswa terhadap suatu konsep yang mereka dapatkan.

Berikut merupakan hasil uji-t dari mathematics anxiety, yaitu:

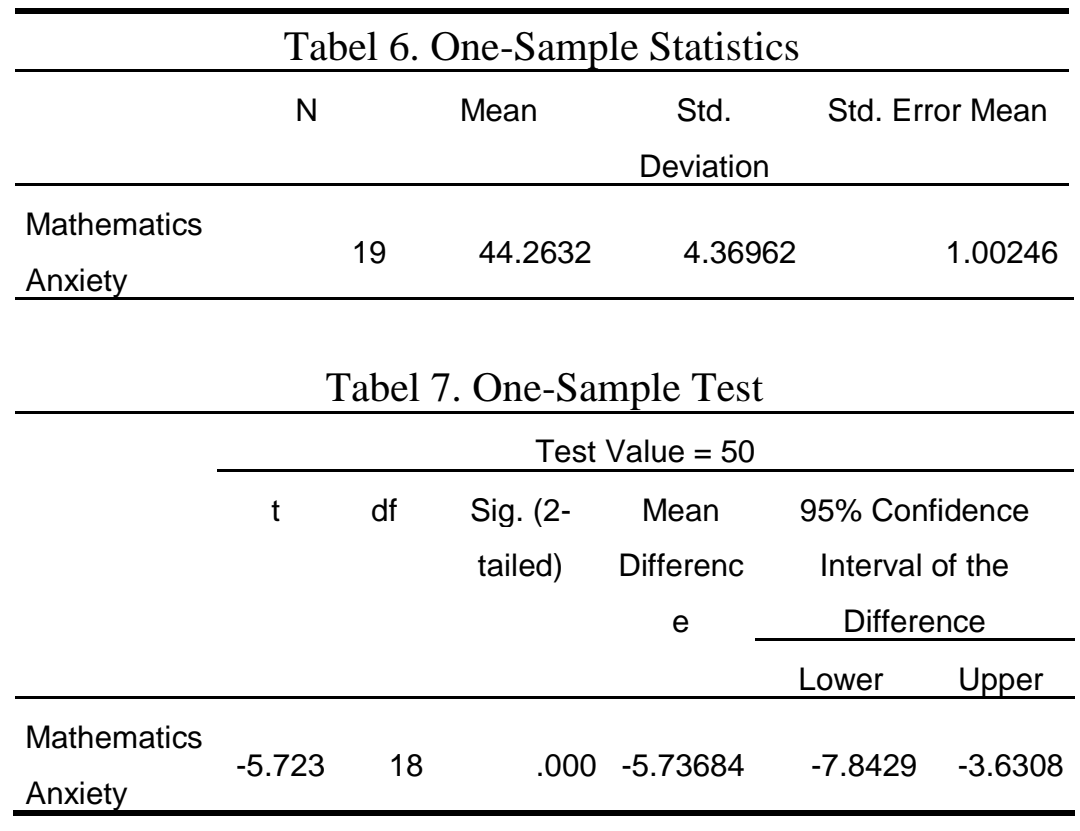

Berdasarkan hasil perhitungan SPSS di atas, diperoleh nilai signifikansi mathematics anxiety $=0,000<0,05$, sehingga dapat diperoleh kesimpulan bahwa terdapat pengaruh model pembelajaran Blended Learning terhadap Mathematics Anxiety. Penelitian ini sejalan dengan penelitian dari (Ganal et al., 2020; Meriyati, Shaulita, \& Nurma Turnip, 2018) yang menjelaskan bahwa mathematics anxiety dapat dipengaruhi oleh penggunaan pembelajaran blended learning.

Dalam kegiatan pelaksanaan pembelajarannya, peneliti memanfaatkan penggunaan aplikasi dari e-learning berupa zoom, email, google schoolar dan whatsapp. Peneliti menjelaskan mengenai bagaimana proses pembelajaran yang akan digunakan, yaitu dengan penggunaan model pembelajaran blended learning kepada mahasiswa. Penjelasan ini bertujuan supaya para mahasiswa mampu menyiapkan diri mereka untuk melakukan proses belajar secara mandiri atau student center. Pada tahap pembelajaran online, mahasiswa dituntut supaya mampu berperan aktif selama mengikuti perkuliahan dan melakukan pembelajaran mandiri, sehingga mereka akan mampu memperoleh pengetahuan dan memahami konsep secara pribadi sehingga mendapatkan hasil yang lebih maksimal.

Mahasiswa mampu mengunduh materi dan tugas perkuliahan tanpa terbatas aspek waktu dan ruang. Dan disini, dosen berperan sebagai fasilitator, dapat mengunggah materi, tugas, hasil evaluasi, serta kelanjutan materi yang akan dipelajari kapan saja. Sehingga, 
proses pembelajaran dapat berlangsung secara multi arah, dimana informasi tidak hanya dari pihak dosen saja, tetapi dari mahasiswa ke dosen, dan mahasiswa dengan mahasiswa lainnya mampu saling berkolaborasi dan membagikan informasi setiap saat. Dengan elearning mahasiswa dapat membiasakan membangun sendiri pengetahuannya sehingga materi terserap dengan baik, membangun karakter saling menolong antar teman yang mengalami kesulitan belajar, serta pemanfaatan waktu yang lebih optimal. Mahasiswa juga dituntut aktif berdiskusi dengan temannya baik ketika dikelas maupun saat pembelajaran online. Hal tersebut sejalan dengan penelitian (Wulandari, Hariadi, Jumadi, Wilujeng, \& Kuswanto, 2019) yang menyebutkan bahwa penggunaan google classroom akan dapat menumbuhkan rasa kerjasama antar dosen dan sesama mahasiswa yang lebih kuat. Selain itu, penelitian ini juga sejalan dengan hasil penelitian (Rahiem, 2020) yang menunjukkan bahwa blended learning pada masa pandemi covid-19 merupakan salah satu alternatif pembelajaran yang mampu menghasilkan perasaan berkomunitas yang lebih kuat antar dosen dan mahasiswa.

\section{KESIMPULAN}

Manfaat pembelajaran blended learning pada tingkatan perguruan tinggi di Indramayu, yaitu pembelajaran blended learning berpengaruh positif terhadap kemampuan berpikir kritis, self concept dan mathematics anxiety calon guru matematika pada masa pandemik Covid-19 di Indramayu. Selain itu, pembelajaran blanded learning dapat dilaksanakan sebagai pilihan untuk kegiatan perkuliahan selama pandemi berlangsung. Hal ini disebabkan karena mampu mengatasi keterbatasan ruang dan waktu antara dosen dan calon guru matematika.

\section{DAFTAR PUSTAKA}

Anggraeni, A., Supriana, E., \& Hidayat, A. (2019). Pengaruh Blended Learning terhadap Kemampuan Berpikir Kritis Siswa SMA pada Materi Suhu dan Kalor. Jurnal Pendidikan, 4(6), 758-763.

Anthony, B., Kamaludin, A., Romli, A., Raffei, A. F. M., Nincarean A/L Eh Phon, D., Abdullah, A., ... Baba, S. (2019). Exploring the role of blended learning for teaching and learning effectiveness in institutions of higher learning: An empirical investigation. Education and Information Technologies, 24(6), 3433-3466. https://doi.org/10.1007/s10639-019-09941-z

Borba, M. C., Askar, P., Engelbrecht, J., Gadanidis, G., Llinares, S., \& Aguilar, M. S. (2016). Blended learning, e-learning and mobile learning in mathematics education. ZDM - Mathematics Education, 48(5), 589-610. https://doi.org/10.1007/s11858-0160798-4

Csp, D., \& Becker, J. L. (2020). Blended Learning Showing Gains. 
Dakduk, S., Santalla-Banderali, Z., \& van der Woude, D. (2018). Acceptance of Blended Learning in Executive Education. SAGE Open, 8(3). https://doi.org/10.1177/2158244018800647

Elyakim, N., Reychav, I., Offir, B., \& McHaney, R. (2019). Perceptions of Transactional Distance in Blended Learning Using Location-Based Mobile Devices. Journal of Educational Computing Research, 57(1), 131-169. https://doi.org/10.1177/0735633117746169

Fadillah, A., Nopitasari, D., Pradja, B. P., Departement, E., \& Tangerang, U. M. (2020). Blended Learning Model During the Covid-19 Pandemic: Analysis of Student ' $s$ ' Mathematical Disposition. 4(2), 173-181.

Faradillah, A., \& Hadi, W. (2020). Educators' Perception of Blended Learning Models on Mathematics Learning. Kalamatika: Jurnal Pendidikan Matematika, 5(1), 83-92. https://doi.org/10.22236/kalamatika.vol5no1.2020pp83-92

Ganal, N. N., Guiab, M. R., \& Strategi, P. (2020). Teaching Strategies and Social Support on Students 'Mathematics Achievement, Attitude, and Anxiety. 1-22.

Hall, M. A. (2006). A decision tree-based attribute weighting filter for naive Bayes.pdf.

Huda, S., Firmansyah, M., Rinaldi, A., Suherman, S., Sugiharta, I., Astuti, D. W., ... Prasetiyo, A. E. (2019). Understanding of Mathematical Concepts in the Linear Equation with Two Variables: Impact of E-Learning and Blended Learning Using Google Classroom. Al-Jabar: Jurnal Pendidikan Matematika, 10(2), 261-270. https://doi.org/10.24042/ajpm.v10i2.5303

Khilmi R, N. (2020). PENGARUH BLENDED LEARNING TERHADAP KEMAMPUAN REPRESENTASI MATEMATIS dan SELF EFFICACY SISWA. AlphaMath : Journal of Mathematics Education, 4(2), 47. https://doi.org/10.30595/alphamath.v4i2.7360

King, G. R. D. (1991). Creswell's Appreciation of Arabian Architecture. In Muqarnas (Vol. 8). https://doi.org/10.2307/1523157

Maryam, I. (2018). Pengaruh Blended Learning Berbantuan Microsoft Mathematic Terhadap Kemampuan Berpikir Kreatif. Jurnal Pendidikan Surya Edukasi (JPSE), 4(2), 23-34. Retrieved from http://ejournal.umpwr.ac.id/index.php/surya/article/view/5340

Meriyati, M., Shaulita, R., \& Nurma Turnip, L. (2018). Problem Based Learning Strategy: the Impact on Mathematical Learning Outcomes viewed from Anxiety Levels. AlJabar: Jurnal Pendidikan Matematika, 9(2), 199-208. https://doi.org/10.24042/ajpm.v9i2.3719

Nugraha, D. G. A. P., Astawa, I. W. P., \& Ardana, I. M. (2019). Pengaruh model pembelajaran blended learning terhadap pemahaman konsep dan kelancaran prosedur matematis. Jurnal Riset Pendidikan Matematika, 6(1), 75-86. https://doi.org/10.21831/jrpm.v6i1.20074

Prihartini, E., Lestari, P., \& Saputri, S. A. (2016). Meningkatkan Kemampuan Berpikir Kritis Matematis Menggunakan Pendekatan Open Ended. Prosiding Seminar Nasional Matematika IX 2015, 58-64.

Rahiem, M. (2020). The Emergency Remote Learning Experience of University Students in Indonesia amidst the COVID-19 Crisis. International Journal of Learning, Teaching and Educational Research, 19(6), 1-26. https://doi.org/10.26803/ijlter.19.6.1

Rahman, R. (2012). Hubungan Antara Self-Concept Terhadap Matematika Dengan Kemampuan Berpikir Kreatif Matematik Siswa. Infinity Journal, 1(1), 19. https://doi.org/10.22460/infinity.v1i1.4

Rasiman. (2006). Seminar Nasional Matematika Dan Pendidikan Matematika Dengan Tema "Penguatan Peran Matematika Dan Pendidikan Matematika Untuk Indonesia Yang Lebih Baik", 185-192. https://doi.org/ISSN : 978 - 979 - 16353 - 9-4 
204 Blended Learning: Kemampuan Berpikir Kritis, Self Concept, dan Mathematics Anxiety Pada Mata Kuliah Aljabar Abstrak

Saputra, H. (2020). Kemampuan Berfikir Kritis Matematis. ResearchGate, 2(April), 1-7.

Silvernail, D. L. (1985). Developing Positive Student Self-Concept. (Second Edition). (2nd ed.; N. E. Publications Department, W. Association, Professional Library, P.O. Box 509, \& C. 06516 Haven, eds.). National Education Association, Washington, D.C.

Wai, C. C., \& Seng, E. L. K. (2015). Measuring the effectiveness of blended learning environment: A case study in Malaysia. Education and Information Technologies, 20(3), 429-443. https://doi.org/10.1007/s10639-013-9293-5

Wulandari, Hariadi, M. H., Jumadi, Wilujeng, I., \& Kuswanto, H. (2019).

Improving Mathematical Representation Ability of Student's Senior High School by Inquiry Training Model with Google Classroom. Journal of Physics: Conference Series, 1233(1). https://doi.org/10.1088/1742-6596/1233/1/012043 